\title{
THE EFFECT OF DIFFERENT ENVIRONMENTAL CONDITIONS ON THE PHYSICAL ACTIVITY OF PRESCHOOL CHILDREN IN ESTONIA
}

\author{
Sirle Nekraš, Mikola Misjuk \\ School of Natural Sciences and Health, Tallinn University, Tallinn, Estonia
}

\begin{abstract}
The purpose of the study is to investigate the effect of different environmental conditions on the physical activity of preschool children. The experiment took place in Estonian childcare centre during the free playtime. Fifteen children aged 6-7 years from childcare centre participated in the research. Physical activity was measured using pedometers Fitbit Zip ${ }^{\mathrm{rm}}$. Results show that in comparison to the usual free play the physical activity of children increased statistically significantly by $83 \%$ when background music was played, by $50 \%$ when sport equipment was provided and by $101 \%$ when both environmental conditions were combined. It was found that compared to the usual free play, children's activity increased the least when only sport equipment was provided, while children's activity increased more when background music was played and increased the most when music with sport equipment was combined. Physical activity did not differ when only background music and music with sport equipment were used. It can be summarised that the background music and opportunity to use portable sport equipment increases the physical activity of children during free play. Background music has greater impact on the activity than portable sport equipment. Children's physical activity can be effectively increased in childcare centre by using simple modifications such as background music and portable sport equipment during free play.
\end{abstract}

Keywords: preschool children, physical activity, childcare centre, free play, environment, sport equipment, background music 


\section{INTRODUCTION}

Insufficient physical activity combined with unsuitable nutrition is causing overweight and obesity already at a very young age and it is becoming more and more topical [14]. Regular physical activity at the preschool age is affecting development of movement skills, is important for developing the habit of physical activity and affects the physical activity at adulthood $[8,10]$. A lot of physical activity comes through play at the preschool age. Games that involve physical activity develop children's speed, endurance, strength and agility; and develop also children's social skills [18].

It is recommended for preschool children to be engaged in organised physical activity at least 60 min every day and engaged in unorganised physical activity at least $60 \mathrm{~min}$ every day. In addition, it is important that children at that age are not physically passive more than 60 minutes in row [15]. It is also recommended that 12000 steps are made every day [5].

The related literature shows that the level of physical activity can vary greatly in childcare centres $[7,17]$. This difference can originate from differences in policies, traditions, study programs, time use and qualification of teachers; but also from the differences in the physical environment in childcare centres $[3,17]$. As a majority of children goes to childcare centres throughout their preschool age and spend the majority of their daytime there, it is important that the time spent there involve also periods of physical activity.

Physical environment plays important role in the physical activity of preschool age children [12]. Related literature has shown that changes made in the physical environment of the childcare centre such as supplying sport equipment and playing music promote children's physical activity $[2,10$, $13,21]$. As the teaching activities undertaken in childcare centres involve by nature a lot of sitting, it is important to design the environment so that it motivates children to be physically more active. One option is to increase children's physical activity by changing the environment during the free play time. Free play time is the time when children are free to choose the activity they like.

There have been studies that have analysed the relationship between environment and children's physical activity $[1,2,10,13,21]$, but this research is specific to the country studied. There are cross-country differences in childcare systems, described by different rules and customs. Studies conducted in different cultural environment can give different results, because children are affected by different rules and customs. This study is conducted in Estonia, where no similar study has been done in childcare centre. 


\section{MATERIALS AND METHODS}

\section{Subjects}

The sample consists of 15 children of whom eight were boys and seven girls. The average age of girls was $6.4 \pm 0.5$ years with average height $125 \pm 7.4 \mathrm{~cm}$ and weight $24.3 \pm 4.3 \mathrm{~kg}$. The average age of boys was $6.6 \pm 0.5$ years with average height $131.1 \pm 10.3 \mathrm{~cm}$ and weight $29.0 \pm 5.6 \mathrm{~kg}$. The girls and boys make one group of subjects in this study.

\section{Procedure}

The experiment was conducted in the rooms of the childcare centre. The permission to undertake the experiment was received from the management of the childcare centre. Only these children participated whose parents gave permission for it. The anthropometric measures of children were taken before the measurement of physical activity. The height of children was measured with an accuracy of $1.0 \mathrm{~cm}$ and weight with an accuracy of $0.1 \mathrm{~kg}$ using electronic scale (Bosch PPW 4200). The experiment was carried out during the free play activity, which is a time when children can choose themselves the activity they like and teachers do not instruct them.

The measurement of physical activity took place in four subsequent Tuesdays and Thursdays, the activity was measured during $60 \mathrm{~min}$ between 10.00 a.m. and 11.00 a.m. in mornings. The duration of the experiment was one month, where during the first week the physical activity was measured in the usual environment that performs as a control. During the second week, the physical activity was measured in the changed environment where music was played to children. During the third week the physical activity was measured in the changed environment where sport equipment was supplied to children and during the fourth week both music and sport equipment were added to the environment.

The experiment was conducted at children's group room in the childcare centre. The room consists of two parts both with a size of $48 \mathrm{~m}^{2}$; the first room is used for teaching, eating and other sitting activities; and the other one for sleeping and playing. Children could use both of the rooms, so in total they had $96 \mathrm{~m}^{2}$ at their disposal.

The music was played as a background music during the free play without intentionally directing children to follow the music. The background music was chosen so that it would satisfy the conditions brought out by Karageorghis et al. [13]: 
- The music has a clear connection to sporting or physical activity - simple and known dancing songs which movements children know.

- The words of the music encourage and motivate - the music has words which tell what moves and how to perform.

- The music takes into account the age and socio-cultural background of participants - pop-songs, songs from films and TV shows that are popular among this age group.

- The tempo of the music is related to physical activity - the songs with higher tempo have proven to increase the level and intensity of physical activity.

The background music was played in a CD of a CD-player. The CD had around 20 music tracks with a total length of $62 \mathrm{~min}$.

The second change in environment was made by sport equipment like portable and easily accessible equipment that stimulate children to move. The set of sport equipment used in this study was developed based on the previous studies $[10,19]$. The following equipment was supplied to children: five balls, five gymnastic rings, two balance boards, the balance track, the tunnel for crawling through and a string-ladder for the floor. The sport equipment was brought to the children's group room and was put to the floor next to the wall. The sport equipment was available for all the children. Children received no instruction to use the sport equipment before the experiment; children were free to choose their activity during the free play time. The security and supervision of children was ensured during the physical activity.

The measurement of children's physical activity during the free play time was made with pedometers Fitbit Zip ${ }^{\mathrm{Tw}}$. The reliability of this pedometer has been confirmed by previous study [20]. Every child received its own pedometer that was equipped with a unique code. The pedometer was set to the right hip of the child by the researcher before the experiment. The children were asked to sit behind the table until all the subjects had received the pedometers. After that, children went to play and were free to choose their activity. After $60 \mathrm{~min}$, the researcher asked children to sit behind the table again, the pedometers were removed, and the scores were fixed. The pedometers were stored at the childcare centre in a private room. The experiment was conducted in all the environments twice, on Tuesday and on Thursday; if a child participated in both of the days; the score with the largest number of steps was used for the statistical analysis. 


\section{Statistical analysis}

The data were processed by MS Excel and the statistical analysis was conducted in statistics software SPSS 23. The ANOVA analysis with repeated measures was used to test whether the average number of steps differs in different physical environments. The LSD post hoc test was implemented to reveal which averages were statistically significantly different from others. The level of confidence was set at $95 \%(\mathrm{p}<0.05)$.

\section{RESULTS}

Figure 1 presents the average values, standard deviations and statistical significance of the steps made by preschool children during different environmental conditions.

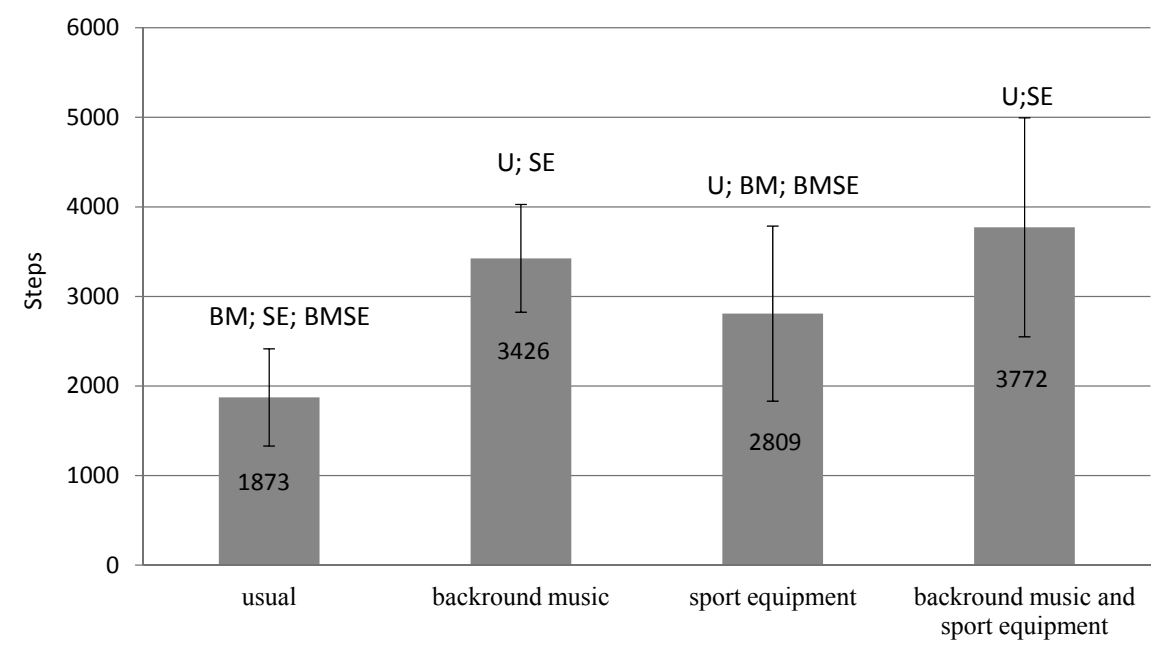

Figure 1. The results of the ANOVA analysis, and the average values and standard deviations of steps made by preschool age children.

$\mathrm{U}$ - statistically significantly different from the usual free time; BM - statistically significantly different from the environment with background music; SE - statistically significantly different from the environment with sport equipment; BMSE - statistically significantly different from the environment with background music and sport equipment $(n=15) . p<0.05$

The results show that the most steps were made in the environment where both, the background music and the sport equipment, was used and the least steps were made in the usual environment. The number of steps was statistically significantly higher in the changed environment compared to the usual environment for all the environmental changes: for the background music 
( $\mathrm{p}=0.000)$, for the sport equipment $(\mathrm{p}=0.013)$, for the background music and the sport equipment $(\mathrm{p}=0.000)$. The number of steps increased by $83 \%$ with the background music compared to the usual environment; by $50 \%$ with the sport equipment; and by $101 \%$ with both the background music and the sport equipment.

In addition, there were significant differences between the tested environmental changes. The number of steps was significantly higher in the environment with the background music compared to the environment with the sport equipment $(\mathrm{p}=0.026)$. The number of steps was also significantly higher in the environment with both, the background music and the sport equipment, compared to the environment with the sport equipment $(\mathrm{p}=0.006)$. There was no significant difference in steps made between the environment with the background music and the sport equipment compared to the environment with only the background music.

\section{DISCUSSION}

This study tested whether the changes in the environment during the free play time affect the physical activity of preschool age children. The background music was chosen as an instrument of change because adding background music to free play time is cheap and easy to implement. The preschool children made $1873 \pm 529$ steps during $60 \mathrm{~min}$ of free play time in the usual environment. The number of steps increased to $3772 \pm 1223$ in the environment where background music and sport equipment were added to the usual environment. Given the recommendations of the World Health Organisation that children should make 12000 steps every day [22], the physical activity of children increased from $15 \%$ of the daily recommended activity to $32 \%$ of the daily recommended activity due to the introduction of the background music and the sport equipment.

The level of steps made in the usual environment is in line with the recommendation that the number of steps in the physical activity class should be around 2000 steps [4]. However, the change in the environment induced significantly higher level of steps than the recommended 2000 steps. This difference in the level of steps can originate from many factors. First, the class of the preschool children was 15 min longer than the class of schoolchildren. Second, sometime of the class is spent on listening the instructions of the teacher in a class of schoolchildren, while the activity of preschool children was not interrupted during the experiment of this study.

The results of this study are in line with earlier studies where the background music played to children at the school age increased the physical 
activity compared to the environment without background music $[1,2]$. It was also found that the physical activity of children increased in the environment where sport equipment was supplied compared to the usual environment. Many earlier studies have shown that supplying various portable sport equipment such as balls, jump ropes, gymnastic rings etc. for children during their free play time increases their physical activity $[9,10,21]$. Comparison of the background music and the sport equipment revealed that the effect of background music on physical activity is larger than the effect of supplying sport equipment.

The earlier studies have also reached different conclusions from ours. There are studies where supplying game and sport equipment has not significantly affected the physical activity of children $[3,6]$. This result can be related to the wider scope of these studies, they were studying the effect of various factors and the stronger effect on children's physical activity came from social factors such as principles of the childcare centre about physical activity, the time spent outside, the fraction of time spent in supervised physical activity and the attitudes of employees. The large effects of environment of physical activity (50-101\%) found in this study can originate from the novelty of these environmental changes, as the background music and sport equipment were never used during the free play time in the childcare centre that participated in the experiment. The novel environment led to large effect but using these environmental changes in a daily basis in the future may not result in so big effect.

As this study and earlier studies have shown that background music and supplying sport equipment increases physical activity of children in the rooms of the childcare centre, the question can be raised why these effective and easy to implement tools are not widely used by childcare centres. The related literature brings out many reasons. Previous studies found that children are more active in their group room if there is room for activity and that the activity is accepted by teachers $[10,11]$. The low physical activity during free play time is often related to the rules in the group room, where more intensive activity is not allowed. There are restrictions for more intensive physical activity as running and jumping in many childcare centres. The aim of these restrictions is to ensure the security of children, but it also leads to more time spent in sitting activities [10].

There are limitations in using the pedometer for measuring physical activity of children. Rowe et al. [16] have brought out that pedometer itself affects children's physical activity. Children start to jump and walk around to see the number of steps increasing on the screen of the pedometer. This affects the behaviour of children especially in the beginning of 
the experiment. Earlier studies have shown that this problem can be avoided if children do not see the number of steps from the screen of the pedometer [16]. The children did not see the number of steps on the screen of the pedometer in this study, while it was observed that children had increased interest in the pedometer at the beginning of the class and that this disappeared during the class.

It can be concluded that the background music and the supply of the sport equipment, and their combination, are effective tools for increasing the physical activity of preschool age children during their free play time when no activities are organised to guide their activity.

\section{REFERENCES}

1. Barney D, Prusak KA. (2015) Effects of music on physical activity rates of elementary physical education students. Physical Educator, 72: 236-244.

2. Bassett J, West S, Shores K. (2011) The effects of Asynchronous music on the physical activities of youth in supervised recreational activities. J Park Recreat Admi, 29: 80-97.

3. Bell AC, Finch M, Wolfenden L, Fitzgerald M, Morgan PJ, Jones J, Freund M., Wiggers J. (2015) Child physical activity levels and association with modifiable characteristics in centre-based childcare. Aust N Z J Public Health, 30: 232-236.

4. Chase B, Morgan H, Brusseau. (2018) Impact of goal setting on physical activity in physical education. J Phys Educ Sport, 111: 757-761.

5. Colley RC, Janssen I, Tremblay M. S. (2012) Daily step target to measure adherence to physical activity guidelines in children. Med Sci Sports Exerc, 44: 977982.

6. Copeland KA, Khoury JC, Kalkwarf HJ. (2016) Child care center characteristics associated with preschoolers physical activity. Am J Prev Med, 50: 470-479.

7. Finn K, Johannsen N, Specker B. (2002) Factors associated with physical activity in preschool children. Journal Pediatr, 140: 81-85.

8. Goldfield GS, Harvey A, Grattan K, Adamo KB. (2012) Physical activity promotion in the preschool years: a critical period to intervene. Int J Environ Res Public Health, 9: 1326-1342.

9. Gordon ES, Tucker P, Burke SM, Carron AV. (2013) Effectiveness of physical activity interventions for preschoolers: a meta-analysis. Res Q Exer Sport, 84: 287-294

10. Gubbels JS, Van Kann DHH, Jansen MWJ. (2012) Play equipment, physical activity opportunities, and children activity levels at childcare. J Environ Public Health, 2012: 326520.

11. Henderson KE, Grode GM, O'Connell ML, Schwartz MB. (2015) Environmental factors associated with physical activity in childcare centres. Int J Behav Nutr Phys Act, 12: 43. 
12. Hinkley T, Crawford D, Salmon J, Okely AD, Hesketh K. (2008) Preschool children and physical activity: A review of correlates. Am J Prev Med, 34: 435-441.

13. Karageorghis CI, Priest DL, Terry PC, Chatzisarantis NLD, Lane AM. (2006) Redesign and initial validation of an instrument to assess the motivational qualities of music in exercise: The Brunel Music Rating Inventory-2. J Sports Sci, 24: 899-909.

14. Kuhl E, Clifford LM, Stark LJ. (2012) Obesity in preschoolers: behavioral correlates and directions for treatment. Obesity, 20: 3-29.

15. National Association for Sport and Physical Education (NASPE). 2009. Active start: A statement of physical activity guidelines for children birth to five years. 2nd ed. Oxon Hill, MD: AAHPERD.

16. Rowe DA, Mahar MT, Raedeke TD, Lore J. (2004) Measuring physical activity in children with pedometers: reliability, reactivity, and replacement of missing data. Ped Exer Sci, 16: 343-354.

17. Sugiyama T, Okely DA, Masters JM, Moore GT. (2012) Attributes of child care centers and outdoor play areas associated with preschoolers physical activity and sedentary behaviour. Environ Behav, 44: 334-349.

18. Timmons BW, Naylor PJ, Pfeiffer KA. (2007) Physical activity for preschool children - how much and how? Can J Public Health, 98: S122-S134.

19. Tucker P, Burke SM, Gaston A, Irwin JD, Johnson AM, Timmons BW, Vanderloo, LM, Driediger M. (2016) Supporting physical activity in the childcare environment (SPACE): rationale and study protocol for a cluster randomized controlled trial. BMC Public Health, 16: 112.

20. Tully M, McBride C, Heron L, Allen W, Hunter, RF. (2014) The validation of Fibit ZipTM physical activity monitor as a measure of free-living physical activity. BMC Research Notes, 7: 952.

21. Verstraete SJ, Cardon GM, De Clercq DL, De Bourdeaudhuij IM. (2006) Increasing children's physical activity levels during recess periods in elementary schools: the effects of providing game equipment. Eur J Public Health, 16: 415-419.

22. World Health Organization. Global recommendations on physical activity for health. Geneva: World Health Organization. (Online) Links valid: http://whqlibdoc.who.int/publications/2010/9789241599979_eng.pdf. (10.10.2018).

\section{Correspondence to:}

Mikola Misjuk, MSc

School of Natural Sciences and Health

Tallinn University

49 Räägu St, 11311 Tallinn, Estonia

E-mail: mikola.misjuk@tlu.ee 